\title{
New methods for understanding systems consolidation
}

\author{
Kaycie K. Tayler ${ }^{1}$ and Brian J. Wiltgen ${ }^{2,3}$ \\ ${ }^{7}$ Department of Psychology, University of Virginia, Charlottesville, Virginia 22904, USA; ${ }^{2}$ Department of Psychology and the Center for \\ Neuroscience, University of California Davis, Davis, California 95618, USA
}

\begin{abstract}
According to the standard model of systems consolidation (SMC), neocortical circuits are reactivated during the retrieval of declarative memories. This process initially requires the hippocampus. However, with the passage of time, neocortical circuits become strengthened and can eventually retrieve memory without input from the hippocampus. Although consistent with lesion data, these assumptions have been difficult to confirm experimentally. In the current review, we discuss recent methodological advances in behavioral neuroscience that are making it possible to test the basic assumptions of SMC for the first time. For example, new transgenic mice can be used to monitor the activity of individual neurons across the entire brain while optogenetic approaches provide precise control over the activity of these cells using light stimulation. These tools can be used to examine the reactivation of neocortical neurons during recent and remote memory retrieval and determine if this process requires the hippocampus.
\end{abstract}

The process by which memories become independent of the hippocampus and are stored in the neocortex is called systems consolidation (Squire 1992; Wiltgen et al. 2004; Frankland and Bontempi 2005; Squire and Bayley 2007). This concept is based on the finding that hippocampus damage impairs recently acquired episodic memories, but does not affect those formed in the distant past (Zola-Morgan et al. 1986; Rempel-Clower et al. 1996; Kapur and Brooks 1999; Bayley et al. 2003; Kirwan et al. 2008; but see Moscovitch et al. 2005; Winocur and Moscovitch 2011). For example, patient E.P. (bilateral hippocampus damage) could remember the city where he was raised 50 yr prior, but was unable to learn about a new neighborhood where he had lived for $6 \mathrm{yr}$ (Teng and Squire 1999). To explain these findings, it was proposed that memory retrieval initially requires the hippocampus because this structure is able to reactivate neocortical regions that were engaged during learning. Over time, continued reactivation strengthens the connections between cortical regions until memory can eventually be retrieved without the support of the hippocampus (Alvarez and Squire 1994; Squire and Wixted 2011). Consistent with this idea, damage to the neocortex (e.g., lateral temporal, frontal) leads to impairments in remote memory (Mangels et al. 1996; Reed and Squire 1998; Murre et al. 2001; Bayley et al. 2003, 2005; Squire and Bayley 2007; Squire and Wixted 2011).

\section{Animal models of systems consolidation}

Systems consolidation has been observed in animals using a number of behavioral procedures (e.g., context fear conditioning, spatial learning, social transmission of food preferences, trace eyeblink conditioning). In these tasks, inactivation of the hippocampus impairs memory retrieval shortly after learning, but has no effect when performed weeks or months later (Kim and Fanselow 1992; Anagnostaras et al. 1999; Clark et al. 2002; Takehara et al. 2002, 2003; Maviel et al. 2004; Ross and Eichenbaum 2006; Lesburgueres et al. 2011; Tayler et al. 2013; but see Clark et al. 2005; Sutherland et al. 2010). In addition, several regions of the neocortex become more important for memory retrieval with the passage of time. Remote memory for context fear, spatial locations, and eyeblink conditioning requires the medial prefron-

\section{${ }^{3}$ Corresponding author}

Email bjwiltgen@ucdavis.edu

Article is online at http://www.learnmem.org/cgi/doi/10.1101/lm.029454.112. tal cortex (Takehara et al. 2003; Frankland et al. 2004; Maviel et al. 2004; Takehara-Nishiuchi and McNaughton 2008; TakeharaNishiuchi et al. 2011), while socially transmitted food preferences depend on the oribitofrontal cortex (Lesburgueres et al. 2011). Increased immediate early gene expression in the neocortex is also observed during remote memory retrieval in these tasks (Maviel et al. 2004; Lesburgueres et al. 2011). As a result, these animal models have been used extensively to examine the neurobiological mechanisms of systems consolidation.

We should note that a growing literature indicates the hippocampus sometimes plays a prolonged role in memory retrieval (Moscovitch et al. 2005; Sutherland et al. 2010; Wiltgen et al. 2010; Winocur and Moscovitch 2011). In context fear conditioning, for example, hippocampus lesions can impair both recent and remote memory (Lehmann et al. 2007). Whether or not systems consolidation occurs appears to depend on the quality of memory that is retrieved during testing and the ability of neocortical regions to compensate when the hippocampus is compromised (Winocur et al. 2007, 2009; Wiltgen et al. 2010; Goshen et al. 2011; Wiltgen and Tanaka 2013). As described in the next sections, new methods for studying memory consolidation can be used to examine these findings and determine how (or whether) they can be integrated with SMC.

\section{Assumptions of SMC}

A number of predictions made by SMC have been confirmed experimentally. Hippocampal and neocortical circuits are reactivated after learning during periods of sleep and inactivity (Wilson and McNaughton 1994; Qin et al. 1997; Siapas and Wilson 1998; Nadasdy et al. 1999; Louie and Wilson 2001; Hoffman and McNaughton 2002). Reactivation during these periods is initiated by sharp wave-ripple complexes (SPW-R) in the CA3 region of the hippocampus (Buzsaki 1989; Chrobak and Buzsaki 1996; Sullivan et al. 2011). Blocking SPW-R events or disrupting the fibers by which they are transmitted to the neocortex impairs the consolidation of recently acquired memories (Daumas et al. 2005; Girardeau et al. 2009; Jadhav et al. 2012).

Studies have also shown that neocortical plasticity is required for memory consolidation (Takehara-Nishiuchi et al. 2006). For example, heterozygous deletion of the $\alpha$ CaMKII gene impairs plasticity and synaptogenesis in the neocortex without affecting hippocampal function. These changes have no effect on 
learning but produce severe memory loss weeks later (Frankland et al. 2001). Consistent with this finding, spine growth in the anterior cingulate and orbitofrontal cortex is necessary for remote memory formation (Lesburgueres et al. 2011; Vetere et al. 2011). Together, these studies indicate that the consolidation of recently formed memories depends on the ability of the neocortex to form new synaptic connections (Frankland and Bontempi 2005). Theta-entrained activity in the hippocampus and neocortex may allow plastic changes to occur that mediate information storage across these networks (Siapas et al. 2005).

Although SMC has been enormously useful, a number of its core assumptions remain untested (Alvarez and Squire 1994). For example, it has not been possible to determine if the same neocortical neurons that were engaged during learning are reactivated months later during memory retrieval. It has also been impossible to selectively manipulate hippocampal neurons that were active during learning and determine if these same cells drive the reactivation of neocortical networks. In the remainder of our review, we focus on the development of new tools that will allow researchers to examine assumptions like these that have been central to theories of memory consolidation for decades (Marr 1971; Alvarez and Squire 1994; McClelland et al. 1995). These include:

Assumption 1: The same neurons that encode memory in the hippocampus and neocortex are reactivated during retrieval.

Assumption 2: Early after learning, the hippocampus drives reactivation of neocortical ensembles during memory retrieval.

Assumption 3: As time passes, neocortical ensembles are reactivated during memory retrieval without input from the hippocampus.

\section{Identification of reactivated neurons}

Immediate early gene (IEG) expression is commonly used to identify activated neurons during learning or retrieval. Expression of these genes is regulated by excitatory synaptic transmission and, in the hippocampus, is closely related to place cell activity (Guzowski et al. 1999; Guzowski 2002; Vazdarjanova et al. 2006). IEGs can also be used to examine reactivation of individual neurons during two separate events. For example, Guzowski and colleagues developed a technique called cellular compartment analysis of temporal activity by fluorescence in situ hybridization (catFISH) that utilized the time course of IEG mRNA transcription to identify reactivated neurons (Guzowski et al. 2005). They found that a large population of hippocampal neurons was reactivated when rats explored the same spatial environment twice within a 20-min period (Guzowski et al. 1999). Reactivation was significantly reduced when animals explored two different environments. Although extremely useful, this technique is limited by the rapid degradation of mRNA. As a result, reactivated neurons can only be identified when sessions occur in close proximity ( 20-30 min).

Reijmers et al. (2007) circumvented the temporal limitations of catFISH by using transgenic mice to label activated neurons. In their mice, the $c$-fos promoter was used to drive expression of the tetracycline transactivator protein (tTA) during learning. tTA expression shows robust overlap with endogenous c-fos in this system (Liu et al. 2012). Activation of the tetO promoter by tTA led to the expression of tau-LacZ, which could be used to identify activated neurons. Activation of the tetO promoter also produced the expression of a doxycycline-insensitive form of tTA, which sustained tau-LacZ activity for several days. As a result, neurons that were labeled during learning could later be identified during testing. During memory retrieval, expression of Zif-268 was used as an indicator of activity. Neurons that were activated during learning and retrieval were double positive for tau-LacZ and Zif-268.

Using a Pavlovian fear conditioning procedure, the authors were able to observe reactivation of individual amygdala neurons when memory was retrieved $3 \mathrm{~d}$ after training. The extent of reactivation in the basolateral nucleus of the amygdala (BLA) correlated with memory strength for context fear, while reactivation in the lateral nucleus of the amygdala (LA) correlated with memory strength for tone fear. Reactivation was significantly lower in mice that did not retrieve memory (fear conditioned-no retrieval group) and in homecage control animals that were not trained or tested.

To examine reactivation of hippocampal and neocortical neurons during context fear conditioning, our laboratory used a transgenic mouse that expresses a long-lasting, activity-dependent form of GFP (Tayler et al. 2011, 2013). In these mice, GFP was fused with the human histone protein HIST1H2BJ (Kanda et al. 1998). The resulting protein (H2BGFP) was localized to the nucleus and remained stable for several weeks after induction. To restrict tagging to neurons that were activated during learning, tetO-H2BGFP mice were bred with the fos-tTA mice described above. C-fos expression was used to identify active neurons during testing.

Consistent with Reijmers et al. (2007), we found robust reactivation of the BLA when mice retrieved a context fear memory $2 \mathrm{~d}$ after training (Tayler et al. 2013). At this same interval, we also observed reactivation of neurons in the dentate gyrus and CA1 subregions of the hippocampus. Several cortical regions involved in spatial and contextual learning were also reactivated (i.e., lateral entorhinal cortex, posterior parietal association area, and the retrosplenial cortex). Neurons in a control brain region, the supplementary motor cortex, were not reactivated when memory was retrieved. In a control experiment we found that reactivation only occurred during memory retrieval; animals trained and tested in different environments did not freeze and showed reactivation levels that did not exceed chance.

Using the H2BGFP transgenic mice, we also examined reactivation of hippocampal and neocortical neurons 2 wk after training. This interval was chosen because memory could be retrieved without the hippocampus at this time point (i.e., systems consolidation had occurred). As predicted by SMC, remote memory retrieval resulted in robust reactivation of cortical neurons that were engaged during learning. However, inconsistent with SMC, we found that neurons in the hippocampus (CA1 and CA3) were also reactivated during remote memory testing. This result was surprising because memory retrieval at this interval did not depend on the hippocampus. According to SMC, the hippocampus should no longer play a role in memory retrieval once systems consolidation has occurred (McClelland et al. 1995; Squire and Alvarez 1995).

It is possible that remote memory retrieval normally involves the hippocampus (which would explain our reactivation data), but can also be mediated by the neocortex if this structure is compromised. A recent study suggests this is the case (Goshen et al. 2011). When the hippocampus was inactivated $28 \mathrm{~d}$ after context fear conditioning, the anterior cingulate cortex showed an increase in activity and became essential for memory retrieval. When cortical compensation was prevented (via rapid optogenetic silencing), remote memory retrieval was dependent on the hippocampus. These results suggest that remote memories can be retrieved by either the hippocampus or the neocortex. Which system is used appears to depend on a number of factors including the passage of time, the presence of reminder cues, and the proliferation of new neurons (Kitamura et al. 2009; Winocur et al. 2009; 
Alvares Lde et al. 2012). Together, these data support a modified version of SMC where neocortical circuits are established after learning, but do not replace the original memory representations stored in the hippocampus (Winocur and Moscovitch 2011; Wiltgen and Tanaka 2013).

The studies just described indicate that neurons in the neocortex are reactivated when memory is retrieved days and weeks after learning. As a result, researchers are now in the position to determine (for the first time) whether reactivation of these neocortical circuits depends on the hippocampus. One way to answer this question is to pharmacologically inactivate the hippocampus during recent and remote memory tests. If SMC is correct, this manipulation should prevent reactivation of cortical regions shortly after learning, but have no effect at longer time intervals. Optogenetic tools could also be used to silence hippocampal neurons during memory retrieval (Goshen et al. 2011; Kheirbek et al. 2013). The advantage of optogenetics is that specific cell populations can be targeted during retrieval. In fact, as described in the last section, recent advances in optogenetics have made it possible to control the activity of neurons that encode a specific context memory.

\section{Alternative tagging methods}

Although the TetTag system is a powerful technique for labeling active neurons it does have several limitations. First, gene expression is dependent on the removal of doxycycline, which can take several days (Glazewski et al. 2001; Reijmers et al. 2007). Active neurons can be labeled anytime during this period, which results in elevated background expression levels relative to other methods (Milanovic et al. 1998; Guzowski et al. 1999; Liu et al. 2012; Tayler et al. 2013). A recent paper addressed this issue by using a novel approach called TRAP: targeted recombination in active populations (Guenthner et al. 2013). In these mice, activitydependent expression of a fluorescent effector gene is dependent on the presence of tamoxifen. When tamoxifen is administered prior to training, CreER ${ }^{\mathrm{T} 2}$ is expressed in active cells and induces excision of a loxP-flanked transcriptional stop signal. This results in ubiquitous expression of a fluorescent protein such as tdTomato. The advantage of this system is that the time window of activation is short $(<12 \mathrm{~h})$ and background expression levels are very low (in FosTRAP mice). In addition, the authors observed a threefold increase in fluorescently labeled hippocampal neurons following exposure to a novel environment. These mice will be extremely useful for long-term labeling studies because activityinduced labeling is permanent.

A second limitation of the TetTag approach is that the percentage of reactivated hippocampal neurons is lower than that reported in catFISH studies. For example, $90 \%$ of labeled CA1 neurons were reactivated when rats explored the same environment twice (Guzowski et al. 1999). In contrast, exposure to two identical environments in TetTag mice induces reactivation of only $20 \%-40 \%$ of CA1 neurons (Nakazawa et al. 2013; Tayler et al. 2013). There are many differences between these experiments (species, procedure, intervals between tests, background labeling) that could account for this difference. However, a recent study by Ziv et al. (2013) used optical imaging to examine place cell reactivation in mice and found that $\sim 25 \%$ of neurons in CA 1 (with active place fields) were reactivated in the same environment $5 \mathrm{~d}$ later. This number decreased slightly over time to $\sim 5 \%$ when sessions were separated by $30 \mathrm{~d}$. In this study, the authors used calcium imaging and a miniaturized head-mounted microscope to monitor neural activity as mice traversed a linear track. This method allowed them to examine thousands of neurons per mouse over a period of several weeks. The fact that reactivation levels in this study are similar to those observed in TetTag mice suggests that the percentage of reactivated neurons is smaller when tests are separated by several days, as opposed to several minutes (as is the case in catFISH experiments). Consistent with this idea, a recent study in rats found that the similarity of neuronal responses in CA1 (during exploration of the same spatial environment) decreased monotonically with the passage of time (Mankin et al. 2012).

\section{Optogenetic control of memory circuits}

Optogenetic techniques can be used to control the activity of specific cell populations. Activation or inactivation is achieved via expression of light-sensitive proteins such as channelrhodopsin (ChR2), halorhodopsin (NpHR), or archaerhodopsin (Arch) (Chow et al. 2010; Yizhar et al. 2011). Recent work has shown that optogenetic methods can also be combined with the tetracycline-transactivator system to control the activity of hippocampal neurons that were engaged during learning (Liu et al. 2012). This is a powerful tool that can be used to examine the contribution of these neurons to systems consolidation.

As described in the previous section, a significant number of hippocampal neurons are reactivated when memory is retrieved. Liu et al. (2012) used optogenetic techniques to provide the first direct evidence that these reactivated neurons mediate memory retrieval. To do so, they infused $\mathrm{AAV}_{9}$-TRE-ChR2-EYFP into the dentate gyrus of fos-tTA mice. By combining these systems they were able to selectively express ChR2 in neurons that were active during contextual fear conditioning. The authors found that subsequent stimulation of these neurons (in a neutral environment) led to memory retrieval (i.e., freezing). Stimulating a similar number of granule cells that were active in a nonshocked context did not produce freezing. These data demonstrate that memory retrieval can be induced by reactivating hippocampal neurons that were engaged during learning.

SMC assumes that neocortical reactivation relies on the hippocampus shortly after learning, but does not require this structure after systems consolidation has occurred. If this idea is correct, then optogenetic stimulation of hippocampal neurons (as performed by Liu et al. [2012]) should lead to neocortical reactivation. This prediction could be tested in the TetTag mice described above (Reijmers et al. 2007; Tayler et al. 2013). Activitydependent expression of tTA would lead to the production of a long-lasting tag (e.g., H2BGFP) and ChR2. Subsequent stimulation of hippocampal neurons would induce memory retrieval and the effects on neocortical reactivation could be examined.

Similarly, a recent study showed that expression of DREADD receptors (designer receptors exclusively activated by designer drugs) could be used to activate neural ensembles that were previously engaged during learning (Garner et al. 2012). In this study, fos-tTA was used to drive the expression of hM3Dq receptors during context learning. Subsequent administration of CNO (clozapine-N-oxide) produced strong depolarization of previously active neurons throughout the brain and led to memory retrieval. Similar experiments could be done in the TetTag mice to selectively stimulate hippocampal ensembles and induce reactivation of neocortical circuits. One limitation of this technique (and optogenetics) is that activated neurons fire in synchrony during stimulation. This artificial type of activity could alter the response of cortical neurons and limit reactivation.

An alternative way to address this issue is to inactivate hippocampal neurons and determine the effects on neocortical reactivation. A recent study showed that NpHR can be used to silence hippocampal neurons and impair context fear memory retrieval (Goshen et al. 2011). In future studies, expression of this protein 
could be restricted to previously active neurons using methods similar to those of Liu et al. (2012). Silencing these neurons in TetTag mice could then be used to determine if hippocampal activity is required for neocortical reactivation during recent memory tests, as predicted by SMC. Inactivating these cells should not impair reactivation of neocortical regions during remote memory tests.

\section{Summary}

Recently developed neuroscience tools are making it possible to test the basic assumptions of SMC. For the first time, we can see that individual neurons across the hippocampus and neocortex are reactivated when memory is retrieved. The activity of these neurons can be monitored for days and weeks after learning in transgenic mice engineered to express long-lasting fluorescent proteins (Reijmers et al. 2007; Guenthner et al. 2013; Tayler et al. 2013). This advance makes it possible to examine reactivation over extended intervals, which is essential for studies of systems consolidation. The activity of labeled neurons can also be controlled with optogenetic techniques. Using this method, researchers were able to show that memory retrieval can be induced by reactivating the same hippocampal neurons that were engaged during learning. Future studies can use chronic in vivo imaging or transgenic mice (TetTag, TRAP) to determine if this manipulation also leads to the reactivation of neocortical circuits. If SMC is correct, hippocampal activity will be essential for neocortical reactivation shortly after learning and become unnecessary at longer intervals.

\section{Acknowledgments}

We thank K. Tanaka and A. Pevzer for comments on earlier versions of this manuscript.

\section{References}

Alvares Lde O, Einarsson EO, Santana F, Crestani AP, Haubrich J, Cassini LF, Nader K, Quillfeldt JA. 2012. Periodically reactivated context memory retains its precision and dependence on the hippocampus. Hippocampus 22: 1092-1095.

Alvarez P, Squire LR. 1994. Memory consolidation and the medial temporal lobe: A simple network model. Proc Natl Acad Sci 91: 7041-7045.

Anagnostaras SG, Maren S, Fanselow MS. 1999. Temporally graded retrograde amnesia of contextual fear after hippocampal damage in rats: Within-subjects examination. J Neurosci 19: 1106-1114.

Bayley PJ, Hopkins RO, Squire LR. 2003. Successful recollection of remote autobiographical memories by amnesic patients with medial temporal lobe lesions. Neuron 38: 135-144.

Bayley PJ, Gold JJ, Hopkins RO, Squire LR. 2005. The neuroanatomy of remote memory. Neuron 46: 799-810.

Buzsaki G. 1989. Two-stage model of memory trace formation: a role for "noisy" brain states. Neuroscience 31: 551-570.

Chow BY, Han X, Dobry AS, Qian X, Chuong AS, Li M, Henninger MA, Belfort GM, Lin Y, Monahan PE, et al. 2010. High-performance genetically targetable optical neural silencing by light-driven proton pumps. Nature 463: $98-102$.

Chrobak JJ, Buzsaki G. 1996. High-frequency oscillations in the output networks of the hippocampal-entorhinal axis of the freely behaving rat. J Neurosci 16: 3056-3066.

Clark RE, Broadbent NJ, Zola SM, Squire LR. 2002. Anterograde amnesia and temporally graded retrograde amnesia for a nonspatial memory task after lesions of hippocampus and subiculum. J Neurosci 22: $4663-4669$.

Clark RE, Broadbent NJ, Squire LR. 2005. Hippocampus and remote spatial memory in rats. Hippocampus 15: 260-272.

Daumas S, Halley H, Frances B, Lassalle JM. 2005. Encoding, consolidation, and retrieval of contextual memory: Differential involvement of dorsal CA3 and CA1 hippocampal subregions. Learn Mem 12: 375-382.

Frankland PW, Bontempi B. 2005. The organization of recent and remote memories. Nat Rev Neurosci 6: 119-130.
Frankland PW, O’Brien C, Ohno M, Kirkwood A, Silva AJ. 2001. $\alpha$-CaMKIIdependent plasticity in the cortex is required for permanent memory. Nature 411: $309-313$.

Frankland PW, Bontempi B, Talton LE, Kaczmarek L, Silva AJ. 2004. The involvement of the anterior cingulate cortex in remote contextual fear memory. Science 304: 881-883.

Garner AR, Rowland DC, Hwang SY, Baumgaertel K, Roth BL, Kentros C, Mayford M. 2012. Generation of a synthetic memory trace. Science 335: 1513-1516.

Girardeau G, Benchenane K, Wiener SI, Buzsaki G, Zugaro MB. 2009. Selective suppression of hippocampal ripples impairs spatial memory. Nat Neurosci 12: 1222-1223.

Glazewski S, Bejar R, Mayford M, Fox K. 2001. The effect of autonomous $\alpha$-CaMKII expression on sensory responses and experience-dependent plasticity in mouse barrel cortex. Neuropharmacology 41: 771-778.

Goshen I, Brodsky M, Prakash R, Wallace J, Gradinaru V, Ramakrishnan C, Deisseroth K. 2011. Dynamics of retrieval strategies for remote memories. Cell 147: 678-689.

Guenthner CJ, Miyamichi K, Yang HH, Heller HC, Luo L. 2013. Permanent genetic access to transiently active neurons via TRAP: Targeted recombination in active populations. Neuron 78: 773-784.

Guzowski JF. 2002. Insights into immediate-early gene function in hippocampal memory consolidation using antisense oligonucleotide and fluorescent imaging approaches. Hippocampus 12: 86-104.

Guzowski JF, McNaughton BL, Barnes CA, Worley PF. 1999. Environmentspecific expression of the immediate-early gene Arc in hippocampal neuronal ensembles. Nat Neurosci 2: 1120-1124.

Guzowski JF, Timlin JA, Roysam B, McNaughton BL, Worley PF, Barnes CA. 2005. Mapping behaviorally relevant neural circuits with immediate-early gene expression. Curr Opin Neurobiol 15: 599-606.

Hoffman KL, McNaughton BL. 2002. Coordinated reactivation of distributed memory traces in primate neocortex. Science 297: 2070-2073.

Jadhav SP, Kemere C, German PW, Frank LM. 2012. Awake hippocampal sharp-wave ripples support spatial memory. Science 336: 1454-1458.

Kanda T, Sullivan KF, Wahl GM. 1998. Histone-GFP fusion protein enables sensitive analysis of chromosome dynamics in living mammalian cells. Curr Biol 8: 377-385.

Kapur N, Brooks DJ. 1999. Temporally-specific retrograde amnesia in two cases of discrete bilateral hippocampal pathology. Hippocampus 9: $247-254$.

Kheirbek MA, Drew LJ, Burghardt NS, Costantini DO, Tannenholz L, Ahmari SE, Zeng H, Fenton AA, Hen R. 2013. Differential control of learning and anxiety along the dorsoventral axis of the dentate gyrus. Neuron 77: 955-968.

Kim JJ, Fanselow MS. 1992. Modality-specific retrograde amnesia of fear. Science 256: 675-677.

Kirwan CB, Bayley PJ, Galván VV, Squire LR. 2008. Detailed recollection of remote autobiographical memory after damage to the medial temporal lobe. Proc Natl Acad Sci 105: 2676-2680.

Kitamura T, Saitoh Y, Takashima N, Murayama A, Niibori Y, Ageta H, Sekiguchi M, Sugiyama H, Inokuchi K. 2009. Adult neurogenesis modulates the hippocampus-dependent period of associative fear memory. Cell 139: 814-827.

Lehmann H, Lacanilao S, Sutherland RJ. 2007. Complete or partial hippocampal damage produces equivalent retrograde amnesia for remote contextual fear memories. Eur J Neurosci 25: 1278-1286.

Lesburgueres E, Gobbo OL, Alaux-Cantin S, Hambucken A, Trifilieff P, Bontempi B. 2011. Early tagging of cortical networks is required for the formation of enduring associative memory. Science 331: 924-928.

Liu X, Ramirez S, Pang PT, Puryear CB, Govindarajan AF, Deisseroth K, Tonegawa S. 2012. Optogenetic stimulation of a hippocampal engram activates fear memory recall. Nature 484: 381-387.

Louie K, Wilson MA. 2001. Temporally structured replay of awake hippocampal ensemble activity during rapid eye movement sleep. Neuron 29: 145-156.

Mangels JA, Gershberg FB, Shimamura AO, Knight RT. 1996. Impaired retrieval from remote memory in patients with frontal lobe damage. Neuropsychology 10: 32-41.

Mankin EA, Sparks FT, Slayyeh B, Sutherland RJ, Leutgeb S, Leutgeb JK. 2012. Neuronal code for extended time in the hippocampus. Proc Natl Acad Sci 109: 19462-19467.

Marr D. 1971. Simple memory: A theory for archicortex. Philos Trans R Soc Lond B Biol Sci 262: 23-81.

Maviel T, Durkin TP, Menzaghi F, Bontempi B. 2004. Sites of neocortical reorganization critical for remote spatial memory. Science 305: 96-99.

McClelland JL, McNaughton BL, O’Reilly RC. 1995. Why there are complementary learning systems in the hippocampus and neocortex: Insights from the successes and failures of connectionist models of learning and memory. Psychol Rev 102: 419-457.

Milanovic S, Radulovic J, Laban O, Stiedl O, Henn F, Spiess J. 1998. Production of the Fos protein after contextual fear conditioning of C57BL/6N mice. Brain Res 784: 37-47. 
Moscovitch M, Rosenbaum RS, Gilboa A, Addis DR, Westmacott R, Grady C, McAndrews MP, Levine B, Black S, Winocur G, et al. 2005. Functional neuroanatomy of remote episodic, semantic and spatial memory: A unified account based on multiple trace theory. J Anat 207: $35-66$

Murre JM, Graham KS, Hodges JR. 2001. Semantic dementia: Relevance to connectionist models of long-term memory. Brain 124: 647-675.

Nadasdy Z, Hirase H, Czurko A, Csicsvari J, Buzsaki G. 1999. Replay and time compression of recurring spike sequences in the hippocampus. J Neurosci 19: 9497-9507.

Nakazawa Y, Pevzer Z, Wiltgen BJ. 2013. Stable reactivation of memory traces in the hippocampus and neocortex. In 2013 Neuroscience meeting planner, Society for Neuroscience, San Diego, CA (in press).

Qin Y, McNaughton B, Skaggs W, Barnes CA. 1997. Memory reprocessing in corticocortical and hippocampocortical neuronal ensembles. Philos Trans R Soc Lond B Biol Sci $\mathbf{3 5 2}$.

Reed JM, Squire LR. 1998. Retrograde amnesia for facts and events: Findings from four new cases. J Neurosci 18: 3943-3954.

Reijmers LG, Perkins BL, Matsuo N, Mayford M. 2007. Localization of a stable neural correlate of associative memory. Science 317: $1230-1233$.

Rempel-Clower NL, Zola SM, Squire LR, Amaral DG. 1996. Three cases of enduring memory impairment after bilateral damage limited to the hippocampal formation. J Neurosci 16: 5233-5255.

Ross RS, Eichenbaum H. 2006. Dynamics of hippocampal and cortical activation during consolidation of a nonspatial memory. J Neurosci 26: $4852-4859$.

Siapas AG, Wilson MA. 1998. Coordinated interactions between hippocampal ripples and cortical spindles during slow-wave sleep. Neuron 21: 1123-1128.

Siapas AG, Lubenov EV, Wilson MA. 2005. Prefrontal phase locking to hippocampal theta oscillations. Neuron 46: 141-151.

Squire LR. 1992. Memory and the hippocampus: A synthesis from findings with rats, monkeys, and humans. Psychol Rev 99: 195-231.

Squire LR, Alvarez P. 1995. Retrograde amnesia and memory consolidation: A neurobiological perspective. Curr Opin Neurobiol 5: 169-177.

Squire LR, Bayley PJ. 2007. The neuroscience of remote memory. Curr Opin Neurobiol 17: 185-196.

Squire LR, Wixted JT. 2011. The cognitive neuroscience of human memory since H.M. Anпu Rev Neurosci 34: 259-288.

Sullivan D, Csicsvari J, Mizuseki K, Montgomery S, Diba K, Buzsaki G. 2011. Relationships between hippocampal sharp waves, ripples, and fast gamma oscillation: Influence of dentate and entorhinal cortical activity. J Neurosci 31: 8605-8616.

Sutherland RJ, Sparks FT, Lehmann H. 2010. Hippocampus and retrograde amnesia in the rat model: A modest proposal for the situation of systems consolidation. Neuropsychologia 48: 2357-2369.

Takehara K, Kawahara S, Takatsuki K, Kirino Y. 2002. Time-limited role of the hippocampus in the memory for trace eyeblink conditioning in mice. Brain Res 951: 183-190.

Takehara K, Kawahara S, Kirino Y. 2003. Time-dependent reorganization of the brain components underlying memory retention in trace eyeblink conditioning. J Neurosci 23: 9897-9905.

Takehara-Nishiuchi K, McNaughton BL. 2008. Spontaneous changes of neocortical code for associative memory during consolidation. Science 322: $960-963$.
Takehara-Nishiuchi K, Nakao K, Kawahara S, Matsuki N, Kirino Y. 2006. Systems consolidation requires postlearning activation of NMDA receptors in the medial prefrontal cortex in trace eyeblink conditioning. J Neurosci 26: 5049-5058.

Takehara-Nishiuchi K, Maal-Bared G, Morrissey MD. 2011. Increased entorhinal-prefrontal theta synchronization parallels decreased entorhinal-hippocampal theta synchronization during learning and consolidation of associative memory. Front Behav Neurosci 5: 90.

Tayler KK, Lowry E, Tanaka K, Levy B, Reijmers L, Mayford M, Wiltgen BJ. 2011. Characterization of NMDAR-independent learning in the hippocampus. Front Behav Neurosci 5: 28.

Tayler KK, Tanaka KZ, Reijmers LG, Wiltgen BJ. 2013. Reactivation of neural ensembles during the retrieval of recent and remote memory. Curr Biol 23: $99-106$.

Teng E, Squire LR. 1999. Memory for places learned long ago is intact after hippocampal damage. Nature 400: 675-677.

Vazdarjanova A, Ramirez-Amaya V, Insel N, Plummer TK, Rosi S, Chowdhury S, Mikhael D, Worley PF, Guzowski JF, Barnes CA. 2006. Spatial exploration induces ARC, a plasticity-related immediate-early gene, only in calcium/calmodulin-dependent protein kinase II-positive principal excitatory and inhibitory neurons of the rat forebrain. J Comp Neurol 498: 317-329.

Vetere G, Restivo L, Cole CJ, Ross PJ, Ammassari-Teule M, Josselyn SA, Frankland PW. 2011. Spine growth in the anterior cingulate cortex is necessary for the consolidation of contextual fear memory. Proc Natl Acad Sci 108: 8456-8460.

Wilson MA, McNaughton BL. 1994. Reactivation of hippocampal ensemble memories during sleep. Science 265: 676-679.

Wiltgen BJ, Tanaka KZ. 2013. Systems consolidation and the content of memory. Neurobiol Learn Mem doi: 10.1016/j.nlm.2013.06.001.

Wiltgen BJ, Brown RA, Talton LE, Silva AJ. 2004. New circuits for old memories: The role of the neocortex in consolidation. Neuron 44: $101-108$

Wiltgen BJ, Zhou M, Cai Y, Balaji J, Karlsson MG, Parivash SN, Li W, Silva AJ. 2010. The hippocampus plays a selective role in the retrieval of detailed contextual memories. Curr Biol 20: 1336-1344.

Winocur G, Moscovitch M. 2011. Memory transformation and systems consolidation. J Int Neuropsychol Soc 17: 766-780.

Winocur G, Moscovitch M, Sekeres M. 2007. Memory consolidation or transformation: Context manipulation and hippocampal representations of memory. Nat Neurosci 10: 555-557.

Winocur G, Frankland PW, Sekeres M, Fogel S, Moscovitch M. 2009. Changes in context-specificity during memory reconsolidation: Selective effects of hippocampal lesions. Learn Mem 16: 722-729.

Yizhar O, Fenno Lief E, Davidson Thomas J, Mogri M, Deisseroth K. 2011. Optogenetics in neural systems. Neuron 71: 9-34.

Ziv Y, Burns LD, Cocker ED, Hamel EO, Ghosh KK, Kitch LJ, Gamal AE, Schnitzer MJ. 2013. Long-term dynamics of CA1 hippocampal place codes. Nat Neurosci 16: 264-266.

Zola-Morgan S, Squire LR, Amaral DG. 1986. Human amnesia and the medial temporal region: Enduring memory impairment following a bilateral lesion limited to field CA1 of the hippocampus. J Neurosci 6: 2950-2967.

Received April 17, 2013; accepted in revised form July 22, 2013. 


\section{Erratum}

Learning \& Memory 20: 553-557 (2013)

\section{New methods for understanding systems consolidation}

Kaycie K. Tayler and Brian J. Wiltgen

In the aforementioned paper, a typographical error changed $\sim 15 \%$ to $\sim 5 \%$ instead (page 555 , six lines from the bottom of column 1). The corrected information is as follows:

However, a recent study by Ziv et al. (2013) used optical imaging to examine place cell reactivation in mice and found that $\sim 25 \%$ of neurons in CA1 (with active place fields) were reactivated in the same environment $5 \mathrm{~d}$ later. This number decreased slightly over time to $\sim 15 \%$ when sessions were separated by $30 \mathrm{~d}$.

We apologize for any confusion this might have caused. 


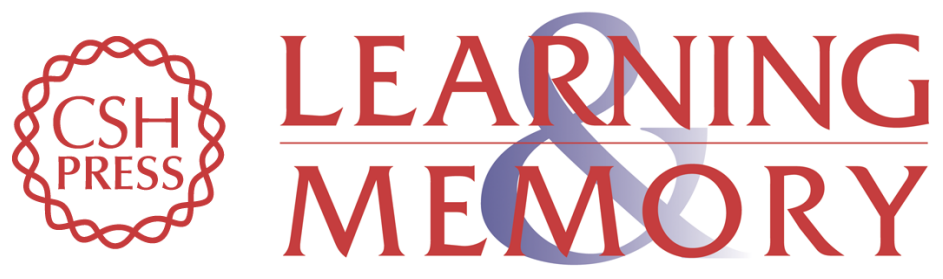

\section{New methods for understanding systems consolidation}

Kaycie K. Tayler and Brian J. Wiltgen

Learn. Mem. 2013, 20:

Access the most recent version at doi:10.1101//m.029454.112

\section{Related Content Erratum}

Learn. Mem. November , 2013 20: 664

References This article cites 75 articles, 27 of which can be accessed free at: http://learnmem.cshlp.org/content/20/10/553.full.html\#ref-list-1

Articles cited in:

http://learnmem.cshlp.org/content/20/10/553.full.html\#related-urls

Creative This article is distributed exclusively by Cold Spring Harbor Laboratory Press for the Commons first 12 months after the full-issue publication date (see

License http://learnmem.cshlp.org/site/misc/terms.xhtml). After 12 months, it is available under a Creative Commons License (Attribution-NonCommercial 3.0 Unported), as described at http://creativecommons.org/licenses/by-nc/3.0/.

Email Alerting

Receive free email alerts when new articles cite this article - sign up in the box at the Service top right corner of the article or click here. 